\title{
Photon-induced Synthesis of Ultrafine Metal Nanoparticles on Graphene as Electrocatalysts: Impact of Functionalization and Doping
}

DOI:

10.1039/C9TA10518B

\section{Document Version}

Accepted author manuscript

Link to publication record in Manchester Research Explorer

Citation for published version (APA):

Guo, K., Rowland, L., Isherwood, L., Glodan, G., \& Baidak, A. (2019). Photon-induced Synthesis of Ultrafine Metal Nanoparticles on Graphene as Electrocatalysts: Impact of Functionalization and Doping. Journal of Materials Chemistry A. https://doi.org/10.1039/C9TA10518B

Published in:

Journal of Materials Chemistry A

\section{Citing this paper}

Please note that where the full-text provided on Manchester Research Explorer is the Author Accepted Manuscript or Proof version this may differ from the final Published version. If citing, it is advised that you check and use the publisher's definitive version.

\section{General rights}

Copyright and moral rights for the publications made accessible in the Research Explorer are retained by the authors and/or other copyright owners and it is a condition of accessing publications that users recognise and abide by the legal requirements associated with these rights.

\section{Takedown policy}

If you believe that this document breaches copyright please refer to the University of Manchester's Takedown Procedures [http://man.ac.uk/04Y6Bo] or contact uml.scholarlycommunications@manchester.ac.uk providing relevant details, so we can investigate your claim.

\section{OPEN ACCESS}




\title{
ARTICLE
}

\section{Photon-induced Synthesis of Ultrafine Metal Nanoparticles on Graphene as Electrocatalysts: Impact of Functionalization and Doping}

Received 00th January 20xx, Accepted 00th January 20xx DOI: $10.1039 / x 0 x \times 00000 x$

\author{
Kun Guo, *ab Laura J. Rowland, ${ }^{\mathrm{a}}$ Liam Isherwood, ${ }^{\mathrm{ab}}$ Gyorgyi Glodan, ${ }^{\mathrm{b}}$ and Aliaksandr Baidak ${ }^{\mathrm{ab}}$
}

\begin{abstract}
Utilizing reducing species generated by high-energy photons offers an alternative strategy to prepare metal nanoparticles (NPs) in the absence of foreign reductant. However, fine control of NP size and dispersity remains a big challenge. Herein, we report that by properly selecting the solvent, precursor concentration and carbon support, ultrafine palladium (Pd) NPs with an average size of $3.0 \mathrm{~nm}$ uniformly distributed on nitrogen-doped graphene (NG) are radiolytically prepared. Control experiments demonstrate that ethylene glycol with moderate reducibility is superior to water. Among four graphene-based supports with distinct functionalization or doping, nitrogen dopants outperform oxygen functional groups in anchoring the NPs and controlling the size and dispersity. Pd/NG also affords the lowest $\eta_{10}$ (overpotential at a current density of 10 $\mathrm{mA} \cdot \mathrm{cm}^{-2}$ ) toward hydrogen evolution reaction (HER). Comparison of Pd/NG with varied Pd loadings indicates that the HER activity nearly reaches a plateau once the loading increases to $2.6 \mathrm{wt} \%$, which is limited by the nitrogen content of NG. Xray photoelectron spectroscopy unambiguously reveals the electron transfer from electron-rich Pd to electron-deficient nitrogen, especially the graphitic nitrogen, corroborating the decisive role of doped nitrogen in stabilizing the Pd NPs on NG. Extending the synthesis to platinum (Pt) yields Pt/NG that presents even lower $\eta_{10}$ than the commercial $10 \mathrm{wt} \% \mathrm{Pt} / \mathrm{carbon}$ black due to the smaller NP size. These results collectively highlight the potential of high-energy photons for green, versatile and scalable synthesis of heterogeneous nanostructures.
\end{abstract}

\section{Introduction}

Green, versatile and scalable synthesis of nanomaterials lays the foundation for the industrial real-world implementation of nanotechnology. The existing synthetic methodologies are deemed as either top-down or bottom-up strategies, which set the stage for the birth of multitudinous nanomaterials. As a bottom-up method, wet-chemical reduction has been prevailingly employed for preparing metal-based nanostructures. ${ }^{1-4}$ However, harsh reaction conditions (high temperature and/or pressure), troublesome surfactants and excess reductants are often required to steer the synthesis, resulting in high cost input and environmental footprint. These deficiencies thus necessitate the development of alternative green and cost-effective synthetic method.

Radiation inclusive of electromagnetic, acoustic and particulate is ubiquitous. Since the pioneering work by Yamazaki and colleagues in $1960 s^{5}$, considerable attempts have been made in exploring the utilization of radiation to prepare nanostructured materials. For instance, Duan and co-workers reported the

\footnotetext{
a. Department of Chemistry, The University of Manchester, Manchester M13 9PL United Kingdom. E-mail: kun.guo-2@manchester.ac.uk\&kun.guo.89@gmail.com b. Dalton Cumbrian Facility, The University of Manchester, Moor Row CA24 3HA, United Kingdom.

Electronic Supplementary Information (ESI) available: Nucleation and growth theory, average crystallite size, results comparison, elemental contents, SEM and TEM images, and XPS spectra. See DOI: 10.1039/x0xx00000x
}

synthesis of graphene-supported single atomic metals with the aid of microwave. ${ }^{6}$ Photochemical reduction, induced by ultraviolet and visible light, has also been utilized to prepare $\mathrm{Ag}^{7-10}, \mathrm{Au}^{11-13}, \mathrm{Pt}^{14-16}$, and $\mathrm{Pd}^{17,18}$ nanostructures. Nonetheless, such radiolytic methods are often kinetically inefficient and thus entail elevated temperature, presence of semiconductor (photoelectron generator) and/or long reaction time. Compared to these non-ionizing radiation, ionizing radiation, such as gamma and $\mathrm{X}$-ray radiation, features high photon energy to more efficiently ionize atoms and break chemical bonds. Therefore, ionizing radiation constitutes a potential powerful method for advanced nanomaterial preparation.

As a highly penetrative electromagnetic wave with the highest photon energy, gamma radiation has been attempted in the wet-chemical preparation of metal ${ }^{19-21}$, oxide ${ }^{22-25}$ and carbonbased materials ${ }^{26-28}$. When the solution concentration is low, solvent is the dominating species that interacts with gamma rays. Radiation chemistry of the corresponding solvents thereby dictates the reaction mechanism. By far, the most frequently studied is the aqueous system. ${ }^{20}$ The radiolytic reaction of water is described in eq 1. ${ }^{20,21}$

$$
\mathrm{H}_{2} \mathrm{O} \stackrel{\text { radiation }}{\longrightarrow} e_{\text {aq }}^{-}, \mathrm{H}_{3} \mathrm{O}^{+}, \mathrm{H}^{*}, \mathrm{OH}^{*}, \mathrm{H}_{2} \text {, and } \mathrm{H}_{2} \mathrm{O}_{2}
$$

The reaction proceeds so efficiently that the radiolysis can be conducted at room temperature and ambient pressure. ${ }^{29}$ Essentially, the species of $e_{a q}^{-}$and $H^{*}$ with low redox potentials serve as in-situ reductants, while the oxidative $O H^{*}$ radical is 
scavenged by common alcohol additives, such as isopropanol and ethanol. Starting from this principle, Zhao and co-workers reported the synthesis of monodispersed $\mathrm{Ag}$ nanoparticles (NPs)/graphene nanocomposites using gamma radiation. ${ }^{30} \mathrm{Pt}$ NPs-decorated reduced graphene oxide ( $\mathrm{rGO}$ ) was similarly fabricated as a counter electrode. ${ }^{31}$ Ag NPs on rGO and titania nanotube arrays were also prepared as photocatalysts. ${ }^{32}$ These trials however fail to deliver surfactant-free NP surface, ultrafine NP size, narrow size distribution, and/or uniform NP dispersity, which unfortunately are paramount attributes for heterogeneous catalysts. Given the three components of the irradiated system (metal precursor, solvent and support), the improvement of radiolytic synthesis thus calls for appropriate selection of the solvent and support materials. Recently, metalorganic frameworks have been used to confine the noble metal $(\mathrm{Pd}, \mathrm{Pt}$ and $\mathrm{Au})$ NPs by utilizing gamma rays with high penetration, yielding an active catalyst for 4-nitrophenol reduction. ${ }^{33}$ Using ethylene glycol (EG) as a solvent, Zhai and coworkers synthesized amorphous $\mathrm{MoS}_{x} / \mathrm{C}$ composites by gamma-ray radiation as efficient electrocatalysts for hydrogen evolution. ${ }^{34}$ These studies rationalize the significance of beyond-water solvent and adequate support in the radiolytic synthesis of heterogeneous catalysts.

Despite the benefits of avoiding foreign reductant, mitigating harsh reaction conditions and high versatility in the NP synthesis using high-energy photons, a systematic study to address issues in controlling the size and dispersity, especially in the absence of surfactants, is still lacking. To this end, we hereby conduct a comprehensive investigation on the effect of solvent, support and metal precursor concentration on the gamma radiolytic synthesis of supported NPs. Instructed by the classical nucleation and growth mechanism, we first justify that EG with mild reducibility and high viscosity is a superior solvent to water. Four graphene materials, including graphene oxide (GO), rGO, nitrogen-doped graphene (NG), and in-house electrochemically exfoliated graphene $(G)$, are scrutinized as potential supports for Pd NPs to reveal the impact of graphene functionalization and doping on support effect. Among them, NG is found to yield an ultrafine Pd NP size with high dispersity and Pd/NG displays the lowest overpotential for the acidic hydrogen evolution reaction (HER). By tuning the Pd loading, we find that the HER activity of Pd/NG levels off once the loading reaches $2.6 \mathrm{wt} \%$. Mechanistic analysis is thus provided to identify the critical role of nitrogen dopants, especially the graphitic nitrogen, in anchoring and stabilizing the formed $\mathrm{Pd}$ NPs by electronic interaction. When replacing Pd with $\mathrm{Pt}, \mathrm{Pt} / \mathrm{NG}$ presents even better HER activity than the commercial $10 \mathrm{wt} \%$ $\mathrm{Pt} / \mathrm{CB}$ catalyst.

\section{Experimental}

\section{Chemicals}

All chemicals were purchased unless otherwise indicated and used as received without further treatment. Chemicals including graphene oxide (GO, sheets), reduced graphene oxide (rGO, chemically reduced by hydrazine), nitrogen-doped graphene (NG, $\geq 4 \%$ nitrogen content), View palladium

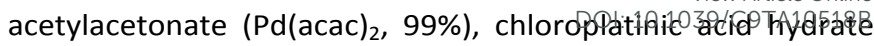
$\left(\mathrm{H}_{2} \mathrm{PtCl}_{6} \cdot \mathrm{xH}_{2} \mathrm{O}, \geq 99.9 \%\right)$, ethylene glycol ( $\mathrm{EG}$, anhydrous, 99.8\%), 2-propanol (IPA, $\geq 99.5 \%$ ), and ethanol (absolute, $\geq 99.8 \%$ ) were purchased from Sigma-Aldrich. Platinum on carbon black (nominally $10 \mathrm{wt} \% \mathrm{Pt} / \mathrm{CB}$, HiSPEC 2000) was supplied by Thermo Fisher Scientific. Electrochemically exfoliated graphene (G) was provided by collaborators and the detailed procedures were described in previous work. ${ }^{35}$ Deionized (DI) water (18.2 $\mathrm{M} \Omega \cdot \mathrm{cm}$ ) was used in all the experiments.

\section{Synthesis of Supported NP Catalysts}

Synthesis of the composites was conducted by exposing the materials to a Cobalt-60 gamma irradiator at Dalton Cumbrian Facility, The University of Manchester. Figure 1 schematically illustrates the one-step radiolytic synthesis. Taking the $2.6 \mathrm{wt} \%$ $\mathrm{Pd} / \mathrm{NG}$ sample as an example, a $20 \mathrm{~mL}$ headspace vial containing $16 \mathrm{~mL}$ of $0.25 \mathrm{M} \mathrm{Pd}(\mathrm{acac})_{2}$ in EG solution and $16 \mathrm{mg}$ of NG was sufficiently sonicated $(\geq 24 \mathrm{~h}$ ) to obtain a homogeneous suspension. After deaeration with argon (N5.0, BOC gas) for 20 min to remove oxygen, the sealed vial was placed inside the irradiator at room temperature and ambient pressure. The radiation was held for $2 \mathrm{~h}$. The total dose was controlled to $\sim 42$ $\mathrm{kGy}$ at a dose rate of $\sim 300 \mathrm{~Gy} \mathrm{~min}^{-1}$. Afterwards, the Pd/NG was separated by centrifugation (Sigma 2-16KL centrifuge) at 15000 rpm for $5 \mathrm{~min}$ and washed with a mixture of ethanol and DI water. After washing for another three times, the composite was dried at $40^{\circ} \mathrm{C}$ in a vacuum oven overnight.

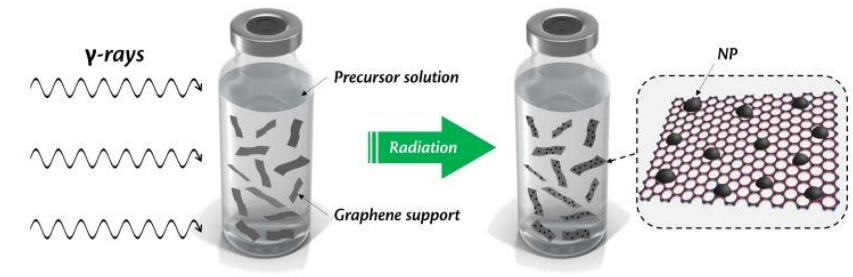

Figure 1. Pictorial illustration of the radiolytic synthesis of graphene-based materials supported Pd NPs in EG.

$\mathrm{Pd} / \mathrm{GO}, \mathrm{Pd} / \mathrm{rGO}$ and $\mathrm{Pd} / \mathrm{G}$ were prepared by replacing the NG with equivalent $\mathrm{GO}, \mathrm{rGO}$ and $\mathrm{G}$, respectively. Using $16 \mathrm{~mL}$ of $0.125,0.375$ and $0.5 \mathrm{M} \mathrm{Pd}(\mathrm{acac})_{2}$ in EG solution, Pd/NG with nominal Pd loadings of $1.3,3.9$ and 5.2 wt \% were prepared, respectively. $2.6 \mathrm{wt} \% \mathrm{Pt} / \mathrm{NG}$ was obtained by replacing Pd with equivalent Pt precursor. $1 \mathrm{mg} \cdot \mathrm{mL}^{-1}$ of $\mathrm{GO}$ dispersions in $\mathrm{EG}$ and DI water (with 2.5 vol. \% IPA) were irradiated to investigate the effect of different solvents.

\section{Physical Characterization}

The microstructure and morphology of supported composite were characterized by transmission electron microscopy (TEM, JEOL JEM-2100F and Thermo Scientific Talos F200X, $200 \mathrm{kV}$ ) and scanning electron microscopy (SEM, Thermo Scientific Quanta $250 \mathrm{FEG}, 10 \mathrm{kV}$ ). For the specimen preparation, one droplet of the composite suspension was dropped onto a copper grid coated with carbon film (400 mesh, TAAB) and dried in air. 
X-ray powder diffraction (XRD) was performed to obtain the crystallographic information of the samples. The powder diffraction patterns were recorded on a Malvern PANalytical XRay diffractometer (Empyrean) using $\mathrm{Cu} K \alpha$ radiation source $(\lambda$ $=1.5406 \AA, 45 \mathrm{kV}$ and $40 \mathrm{~mA}$ ). Scanning angles for all samples were set in the $2 \vartheta$ range of $10-90^{\circ}$ with a step size of $0.01313^{\circ}$ and time per step of $120 \mathrm{~s}$. Peaks were indexed according to the database established by Joint Committee on Powder Diffraction Standards (JCPDS).

Raman spectrum was obtained using a confocal Raman microscope (SENTERRA II, Bruker) equipped with an optical microscope, a CCD camera and an argon ion laser source. The laser provided $2 \mathrm{~mW}$ power at a wavelength of $532 \mathrm{~nm}$ for the exciting line. Integration time was $60 \mathrm{~s}$, number of co-addition was 4 and slit aperture size was $50 \times 1000 \mu \mathrm{m}$.

Attenuated total reflection Fourier transform infrared (ATRFTIR) spectroscopy was carried out on a Bruker VERTEX 70 spectrometer by using a DigiTect DLaTGS detector and platinum ATR. All spectra were recorded with a resolution of $2 \mathrm{~cm}^{-1}$ for 200 scans in the spectral range between $\tilde{v}=400$ and $4000 \mathrm{~cm}^{-1}$. The background spectrum of air was measured as a single beam and used as reference.

X-ray photoelectron spectroscopy (XPS) analysis was performed on the Nexsa X-Ray Photoelectron Spectrometer (XPS) System (Thermo Fisher Scientific) utilizing a monochromatic Al K $\alpha$ source (1486.69 eV). High-resolution spectra were obtained at a pass energy of $40.0 \mathrm{eV}$, a step size of $0.1 \mathrm{eV}$, and a dwell time of $50 \mathrm{~ms}$ per step. The analysis spot size was $100 \times 200 \mu \mathrm{m}$. All spectra were calibrated to the $\mathrm{C} 1 \mathrm{~s}$ peak ( $284.5 \mathrm{eV})$. XPS peaks were deconvoluted and curve-fitted on CasaXPS software.

\section{Electrochemical Characterization}

Electrochemical measurements were conducted on an Autolab PGSTAT101 potentiostat (Metrohm U.K. Ltd.) in a standard three-electrode cell at room temperature. A glass carbon electrode ( $\mathrm{GCE}$, diameter of $3 \mathrm{~mm}$ ), $\mathrm{Ag} / \mathrm{AgCl}$ in $3 \mathrm{M} \mathrm{KCl}$ electrode and platinum foil were used as working, reference and counter electrode, respectively. $0.5 \mathrm{M} \mathrm{H}_{2} \mathrm{SO}_{4}$ solution was used as the electrolyte. All the potentials were calibrated to the reversible hydrogen electrode (RHE), according to Nernst equation $E_{v s} R H E$ $=\mathrm{E}_{\mathrm{vs} \mathrm{Ag} / \mathrm{AgCl}}+0.21+0.0592 \times \mathrm{pH}$. The geometric area of GCE was $0.0707 \mathrm{~cm}^{2}$, which was used to calculate the current density in the linear sweep voltammetry (LSV).

Modified working electrode was fabricated via the following procedure: $5 \mathrm{mg}$ of as-prepared catalyst or commercial Pt/CB was dispersed in a mixture of $600 \mu \mathrm{L}$ of DI water, $300 \mu \mathrm{L}$ of ethanol and $100 \mu \mathrm{L}$ of $5 \mathrm{wt} \%$ Nafion solution. The mixture was ultrasonically stirred for at least $2 \mathrm{~h}$ to obtain a homogeneous suspension. Then $3 \mu \mathrm{L}$ of the suspension was taken by a microsyringe and drop-casted onto a clean GCE with an overall loading of $0.212 \mathrm{mg} \cdot \mathrm{cm}^{-2}$. The modified GCE was dried naturally in air. Prior to the LSV test, the electrochemical cell was saturated with argon for at least $30 \mathrm{~min}$ and the modified GCE was activated by applying a cyclic voltammetry (CV) method in the potential range of 0 to $0.5 \mathrm{~V}_{\mathrm{RHE}}$ for 50 cycles at a scan rate of $200 \mathrm{mV} \cdot \mathrm{s}^{-1}$. The LSV scan potential was set in the range of
-0.4 to $0.1 \mathrm{~V}_{\mathrm{RHE}}$ and the scan rate was $5 \mathrm{mV} \cdot \mathrm{s}^{-1}$. All polarization curves were presented without iR compensaltion.039/C9TA10518B

\section{Results and discussion}

\section{Effect of Solvent and Precursor Concentration}

According to the classical nucleation and growth theory ${ }^{36}$, in a homogeneous system, metal cations are first reduced to give a high supersaturation of monomers, which leads to a burst of nuclei. Competition between bulk energy and surface energy then drives either the dissolution of nuclei back to monomers or the growth of nuclei into larger sizes. Lastly, the Ostwald ripening occurs due to the minimization of the overall surface energy. However, graphene supports in the raw solution can adsorb the metal nuclei or nanoparticles to reduce the surface energy and hinder the monomer diffusion. Therefore, in the radiolytic synthesis, the final size and distribution of Pd NPs shall mainly be determined by the nucleation and growth.

From the expression of critical nucleus radius $r_{c}$, as detailed in Note $S 1$, we see that $r_{c}$ is dependent on the supersaturation $S$. A relatively large $r_{c}$ is preferred to prevent nuclei from easily overcoming the energy barrier and growing into large-sized particles. This strategy has been applied to prepare even single atomic catalyst. ${ }^{37}$ Upon gamma radiation, reducing species are generated from the solvent by high-energy photons to rapidly convert Pd ions into monomers. It is thus speculated that the generation rate of reducing species from the solvent and the metal precursor concentration play a critical role in triggering and controlling the nucleation and growth of Pd NPs.

We first compare the reducibility of two common solvents, $\mathrm{H}_{2} \mathrm{O}$ and $E G$, in the radiolytic reduction of $\mathrm{GO} .1 \mathrm{mg} \cdot \mathrm{mL}^{-1}$ of $\mathrm{GO}$ dispersed in $\mathrm{H}_{2} \mathrm{O}-\mathrm{IPA}(\mathrm{v} / \mathrm{v}=39 / 1)$ or $\mathrm{EG}$ are prepared by mechanical sonication and stirring, and subsequently irradiated under gamma rays for $6 \mathrm{~h}$ with a total dose of $\sim 120 \mathrm{kGy}$. Figure 2 shows the ATR-FTIR and Raman spectra of pristine and irradiated GO. In Figure 2a, typical functional groups are observed for the pristine GO. When $\mathrm{GO}$ is irradiated in $\mathrm{H}_{2} \mathrm{O}$, these functional groups are substantially removed, indicating the efficient reduction. Whereas, GO irradiated in EG shows no major changes in these functional groups. Figure $2 \mathrm{~b}$ presents their Raman spectra. Two distinct peaks appearing at 1345 and $1588 \mathrm{~cm}^{-1}$ for all the $\mathrm{GO}$ samples are discerned, representing the $D$ and $G$ peaks, respectively. The $D$ band stems from vibrational modes of carbon atoms around the edges and defects, manifesting the presence of structural disorder. The $\mathrm{G}$ band originates from the in-plane vibrational modes of $\mathrm{sp}^{2}$ hybridized carbon atoms in the graphene layer. ${ }^{38,39}$ The band intensity ratio $\left(\mathrm{I}_{\mathrm{D}} / \mathrm{I}_{\mathrm{G}}\right)$ is often used as a descriptor of the graphitization degree of carbon materials. There are two opposing effects that cause the change of $\mathrm{I}_{\mathrm{D}} / \mathrm{I}_{\mathrm{G}}$ ratio of $\mathrm{GO}$. Mechanical sonication and stirring break the graphene sheets into smaller pieces with more edges, resulting in a decrease in the average size of the in-plane $\mathrm{sp}^{2}$ domains and thus an increase of $\mathrm{I}_{\mathrm{D}} / \mathrm{I}_{\mathrm{G}}$ ratio. On the contrary, reduction of $\mathrm{GO}$ by irradiation remove the oxygen groups and $\mathrm{sp}^{3}$-hybridized carbon atoms turn into $\mathrm{sp}^{2}$ carbon, leading to a decrease of $\mathrm{I}_{\mathrm{D}} / \mathrm{I}_{\mathrm{G}}$ 
ratio. Figure $2 \mathrm{c}$ shows that $\mathrm{GO}$ irradiated in $\mathrm{H}_{2} \mathrm{O}$ has a higher $\mathrm{I}_{\mathrm{D}} / \mathrm{I}_{\mathrm{G}}$ ratio $(1.08)$ than pristine $\mathrm{GO}(0.92)$, whereas $\mathrm{GO}$ irradiated in $E G$ has an $I_{D} / I_{G}$ ratio (1.00) close to pristine $G O$. The increased $I_{D} / I_{G}$ ratios of both irradiated $G O$ can be attributed to the dominant effect of mechanical breakage of $\mathrm{GO}$ on the $\mathrm{I}_{\mathrm{D}} / \mathrm{I}_{\mathrm{G}}$ ratio. This is confirmed by their SEM images in Figure S1, in which we can see flat and large-sized GO changes to fluffy sheets with more edges after radiation. Meanwhile, despite that GO irradiated in $\mathrm{H}_{2} \mathrm{O}$ is significantly reduced, the mechanical fracture shall be more intense to compensate the restoration for $\mathrm{GO}$ in $\mathrm{H}_{2} \mathrm{O}$ than $\mathrm{GO}$ in $\mathrm{EG}$, which should be attributed to the different dispersity of $\mathrm{GO}$ in $\mathrm{H}_{2} \mathrm{O}$ and $\mathrm{EG}$. These results indicate that $\mathrm{EG}$ has a relatively moderate reducibility and is a more appropriate solvent than $\mathrm{H}_{2} \mathrm{O}$ for preparing metal NPs by gamma radiation. Therefore EG is selected as the solvent throughout the remainder of this study.
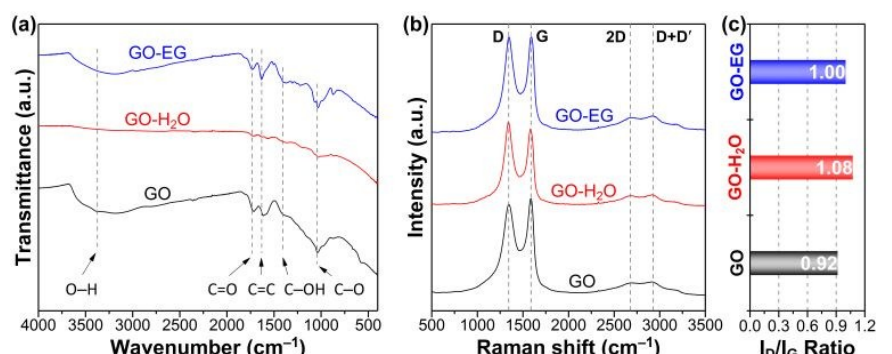

Figure 2. ATR-FTIR spectra (a), Raman spectra (b), and $I_{D} / I_{G}$ ratios of pristine $G O, G O$ in $\mathrm{H}_{2} \mathrm{O}$, and $\mathrm{GO}$ in $\mathrm{EG}$ after gamma radiation.

Effect of metal precursor concentration on NP size is also roughly explored by irradiating 1 and $2 \mathrm{mM} \mathrm{Pd(acac})_{2}$ in EG containing $1 \mathrm{mg} \cdot \mathrm{mL}^{-1}$ of $\mathrm{GO}$ as support. No external surfactant is added. Figure S2 shows the representative SEM images of $\mathrm{Pd} / \mathrm{GO}$ samples. According to the SEM principle, secondary electrons are the most common signals, which closely correlate to the sample conductivity. ${ }^{40}$ The bright area is attributed to the formed Pd metal with high conductivity while the dark area should be the GO with poor conductivity. We can see the formation of micron-sized Pd aggregates when using $2 \mathrm{mM}$ $\mathrm{Pd}(\mathrm{acac})_{2}$ (Figure S2a). Despite lowering the concentration to 1 $\mathrm{mM} \mathrm{Pd}(\mathrm{acac})_{2}$ effectively reduces the aggregation, small amount of micron particles are still observed (Figure S2b). In light of this, the metal precursor concentration should be kept below $1 \mathrm{mM}$ to avoid severe segregation when no surfactant is present.

\section{Pd NPs on Different Supports}

When support materials are present in the solution, the nucleation and growth is energetically favored at structural inhomogeneties, such as support edges and defective sites. ${ }^{41}$ Benefiting from the high conductivity, large surface area and flexible surface chemistry, graphene materials, either functionalized by oxidation or doped with heteroatom, are widely used supports. ${ }^{42-44}$ Nitrogen dopants in NG have been disclosed to stably anchor the metal NPs, even at atomic scale as $\mathrm{M}-\mathrm{N}_{4}-\mathrm{C}$ moieties. ${ }^{45,46}$ It is thus interesting to investigate the effect of NG on controlling the size and dispersion during radiolytic synthesis of metal NPs. Besides, velectrostatic interaction between the support and preeursor ifores shoupd 1BB considered. ${ }^{47,} 48$ To this end, GO, rGO and $\mathrm{G}$ are utilized as comparison since the zeta potential of these supports varies from negative to positive.

Figure 3 shows the XRD patterns of four pristine supports and $0.25 \mathrm{mM} \mathrm{Pd}(\mathrm{acac})_{2}$ and $1 \mathrm{mg} \cdot \mathrm{mL}^{-1}$ of support in EG. The nominal $\mathrm{Pd}$ loading is $2.6 \mathrm{wt} \%$ provided the support remain intact after radiation. For the GO support, the (001) peak at 2 theta of $\sim 10^{\circ}$ is still present while (002) peak at 2 theta of $\sim 22^{\circ}$ shifts to $\sim 25^{\circ}$ after gamma irradiation, indicating $\mathrm{GO}$ is slightly reduced and a small amount of functional groups are removed. Meanwhile, five characteristic peaks at 2 theta of $40,46,68,82$, and $86^{\circ}$ are indexed to JCPDS card No. 87-0643, corresponding to (111), (200), (220), (311), and (222) crystal planes of metallic Pd. On the contrary, no obvious variations are observed for the $\mathrm{rGO}, \mathrm{G}$ and NG supports before and after radiation, manifesting their high structural stability. In addition, relatively small diffraction peaks of $\mathrm{Pd}$ are detected for $\mathrm{Pd} / \mathrm{rGO}, \mathrm{Pd} / \mathrm{G}$ and $\mathrm{Pd} / \mathrm{NG}$. The broad diffraction peak suggests small crystalline domains or amorphous nature of the Pd, as shown in Table S1 for the average crystallite sizes, which is expected since the radiation is performed at room temperature. Heat transfer resulted from the gamma radiation for $2 \mathrm{~h}$ is tested to be negligible.

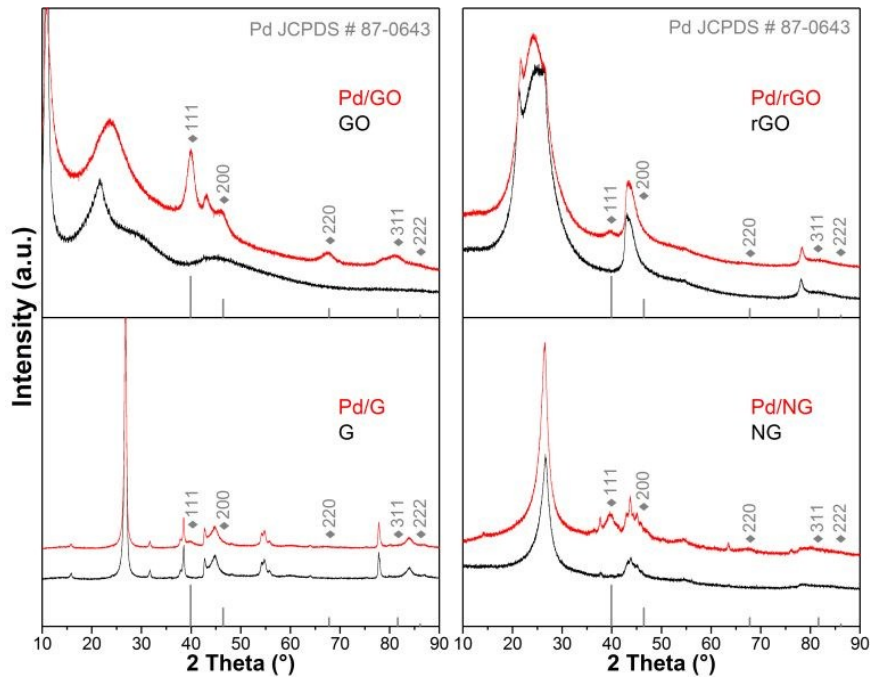

Figure 3. XRD patterns of the pristine supports and corresponding $\mathrm{Pd}$ supported composites: (top left) Pd/GO and GO, (top right) Pd/rGO and rGO, (bottom left) Pd/G and $G$, and (bottom right) Pd/NG and NG.

XPS technique is used to acquire elemental and compositional information of the supported composites and pristine supports. Full survey XPS spectra in Figure S3 confirms their elemental compositions of $\mathrm{C}, \mathrm{O}, \mathrm{N}$, and/or Pd. Figure 4 compares their high-resolution XPS spectra of the $\mathrm{C}$ 1s region. The deconvoluted peaks in different colors indicate the distinct oxygen functionalization and nitrogen doping. For instance, GO contains $\mathrm{sp}^{2}$ hybridized $\mathrm{C}, \mathrm{C}-\mathrm{O}, \mathrm{C}=\mathrm{O}, \mathrm{O}-\mathrm{C}=\mathrm{O}$, and $\mathrm{C}-\mathrm{H}$. After radiation, $\mathrm{C}-\mathrm{H}$ species is removed and $\mathrm{C}-\mathrm{O}$ species of $\mathrm{Pd} / \mathrm{GO}$ is dramatically reduced. $\mathrm{rGO}$ has much less $\mathrm{O}$-containing groups relative to $\mathrm{GO}$ and no major difference is observed compared to $\mathrm{Pd} / \mathrm{rGO}$. Note that $\mathrm{rGO}$ is prepared by hydrazine reduction 
according to the description of the supplier. During the reduction, hydrazine reacts with carbonyl groups to form hydrazone but barely reacts with hydroxyl or carboxyl groups. ${ }^{49-}$ 51 rGO thus shall contain residual oxygen groups and incorporated nitrogen atoms. These nitrogen species exist as functional groups (amino and imine groups) mostly at the graphene edges instead of being randomly doped into the basal plane of graphene. $\mathrm{G}$ and NG contain mostly $\mathrm{sp}^{2}$ hybridized $\mathrm{C}$ except the $\mathrm{C}-\mathrm{N}$ peak in NG. Both of them also remain largely identical after being irradiated. Table S2 details the atomic and weight percentage of $\mathrm{C}, \mathrm{N}, \mathrm{O}$, and $\mathrm{Pd}$ for the pristine supports and supported composites. It is confirmed that $\mathrm{O}$ content of $\mathrm{GO}$ is substantially reduced while $\mathrm{rGO}, \mathrm{G}$ and NG remain mostly unchanged after radiation. However, the $\mathrm{Pd}$ content varies from 1.1 wt \% for $\mathrm{Pd} / \mathrm{GO}$ and $\mathrm{Pd} / \mathrm{rGO}$ to $10.1 \mathrm{wt} \%$ for $\mathrm{Pd} / \mathrm{NG}$, as shown in Figure $\mathrm{S} 4$ in reference to the nominal value of $2.6 \mathrm{wt}$ $\%$. This unexpected result can be explained by the immobilization of Pd NPs on the outmost surface of support and the nature of XPS analysis. XPS only determines elemental compositions from the outmost surface up to a depth of several nanometers of the sample. It is rational to have higher $\mathrm{Pd}$ content on the surface than the nominal value that takes $\mathrm{Pd}$ and support as an integrity. Meanwhile, for Pd/GO and Pd/rGO, $\mathrm{Pd}(\mathrm{II})$ could be partially reduced and loaded on the supports, giving lower Pd loadings. It also demonstrates that $\mathrm{N}$-containing groups (amino and imine groups) in $\mathrm{rGO}$ are less competitive than doped nitrogen species in anchoring the Pd NPs when comparing $\mathrm{Pd} / \mathrm{rGO}$ and $\mathrm{Pd} / \mathrm{NG}$. In light of this, the O-containing groups on functionalized graphene should hold accountable because of the potential re-oxidation/dissolution of $\mathrm{Pd}$ by $\mathrm{O}-$ containing groups and/or adverse electrostatic interaction between the negatively charged support and Pd NPs. ${ }^{52,53}$

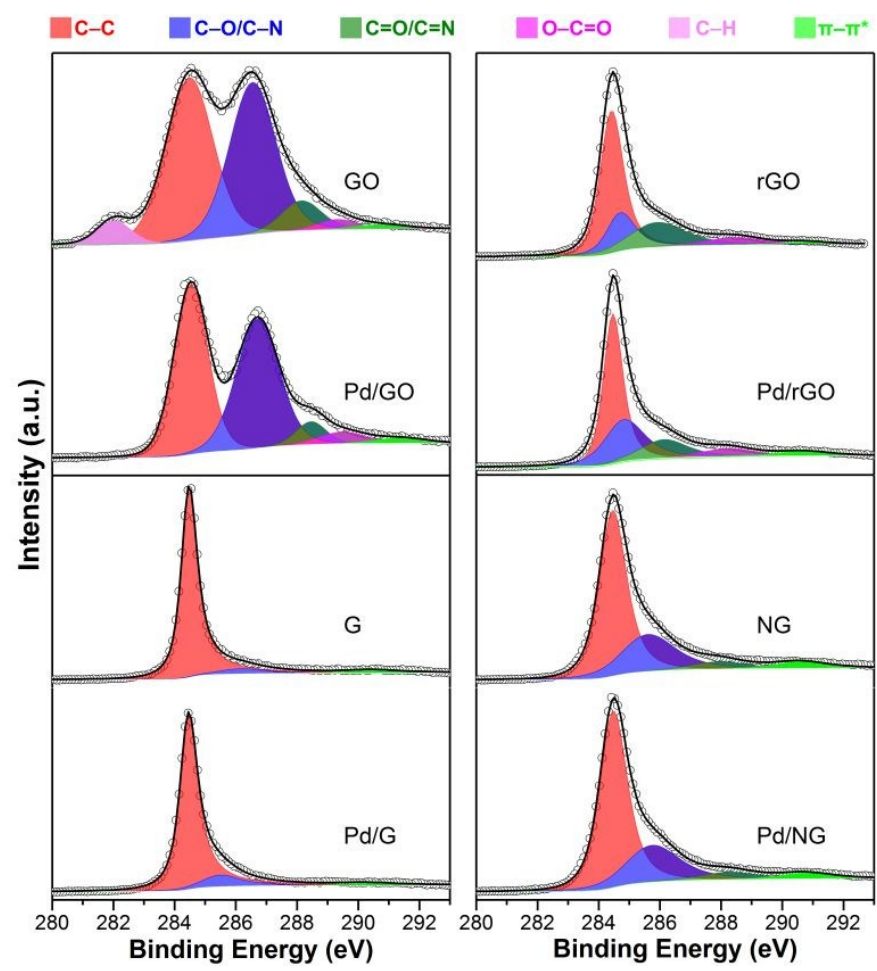

This journal is (C) The Royal Society of Chemistry 20xx
Figure 4. High-resolution XPS spectra of $C$ 1s region for the pristine supports and corresponding Pd supported composites: (top left) Pd/GQ and 19.90 ( and $\mathrm{rGO}$, (bottom left) Pd/G and G, and (bottom right) Pd/NG and NG.

To visually observe the size and distribution of $\mathrm{Pd}$ on NG support, TEM analysis of Pd/NG is conducted. Figure 5a shows a representative bright field TEM image of the Pd/NG. Uniform distribution of Pd NPs immobilized on the surface of NG is discerned. Based on a statistic count of particle size $(>500$ counts) and subsequent Gauss fit (Figure 5b), an ultrafine average particle size (APS) of $3.0 \pm 0.6 \mathrm{~nm}$ is determined and a narrow particle size distribution (PSD) is confirmed. TEM images and the corresponding PSDs of Pd NPs on GO, rGO and G are presented in Figure S5. The larger APS than average crystallite size (Table S1) for each composite signifies the multicrystalline nature of all Pd NPs. In contrast to Pd/NG, Pd NPs are either sparsely anchored on $\mathrm{GO}$ and $\mathrm{rGO}$ with a relatively small quantity, or severely aggregated on $\mathrm{G}$, conforming well to the elemental percentage by XPS analysis. These results indicate the superior role of NG to the other supports in size controlling and uniform loading of Pd NPs. Comparison of solvent, surfactant and APS in the radiolytic synthesis of Pd/NG in this study and results in the literature is detailed in Table S3 and plotted in Figure S6. We clearly see that the APS and PSD of Pd NPs on NG are superior to most of the other metal particles and among the best when no surfactant is employed, highlighting the merits of our synthetic method. Although $\mathrm{H}_{2} \mathrm{O}$ has been prevailingly used as the solvent, the ultrafine Pd NPs on Pd/NG demonstrate that EG can be more competitive in the control of size and dispersity of NPS. SEM images of pristine supports and the composites are shown in Figure S7. Severe fracture is again observed for $\mathrm{GO}$ after radiation, whereas no obvious variation is discerned for $\mathrm{rGO}, \mathrm{G}$ and NG supports.
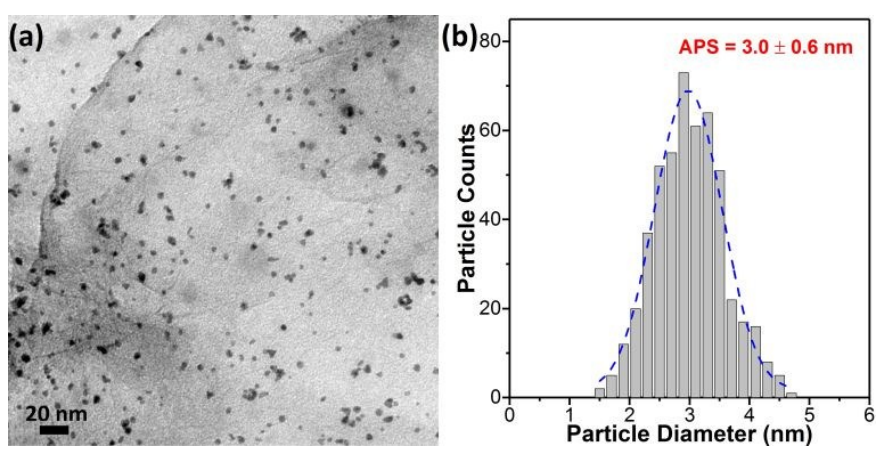

Figure 5. Representative bright field TEM image (a) and corresponding particle size distribution curve (b) of the Pd/NG based on statistical counts.

Raman spectra of the supports and supported composites are examined for further structural information. Figure 6 presents the Raman spectra and calculated $I_{D} / I_{G}$ ratios before and after the radiation. The $D$ and $G$ bands are clearly shown for all the graphene-based materials. For the $\mathrm{G}$ and $\mathrm{Pd} / \mathrm{G}$, a strong $2 \mathrm{D}$ band is observed, indicating the small layer number of $G$. However, the other GO, rGO and NG show no appreciable 2D band, which suggests the stacking of graphene sheets with relatively large layer numbers. ${ }^{39}$ The quality of commercial graphene-based materials has also been questioned 
previously. ${ }^{54}$ Moreover, the $\mathrm{I}_{\mathrm{D}} / \mathrm{I}_{\mathrm{G}}$ ratios largely remain consistent for the GO, rGO and NG supports, whereas GO exhibits a slight increase in $I_{D} / I_{G}$ ratio after radiation, which agrees with the results in Figure $2 \mathrm{~b}$ and $2 \mathrm{c}$.
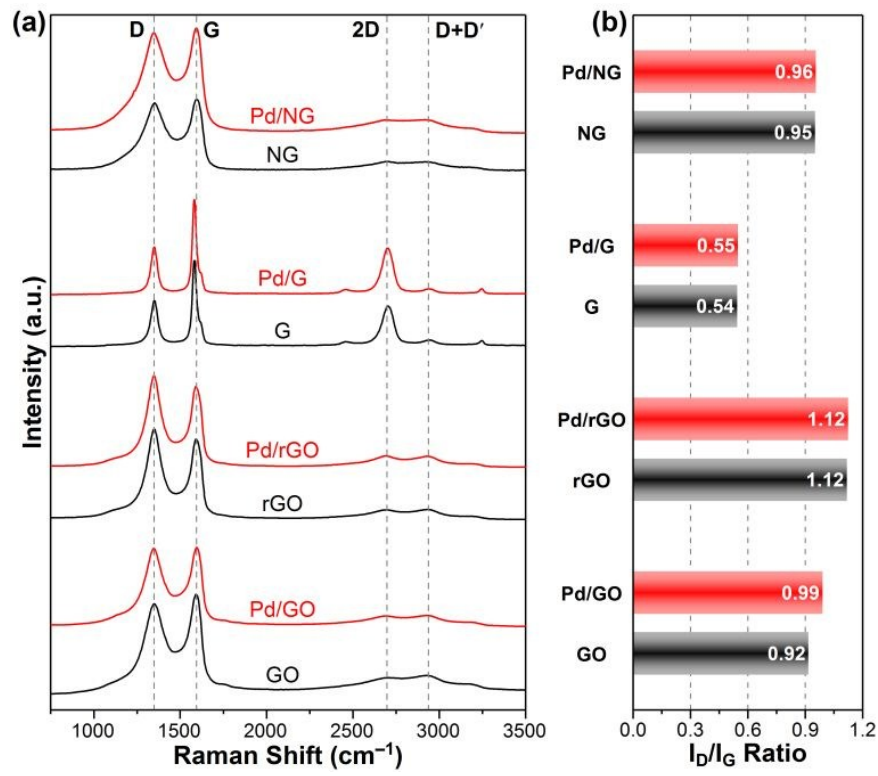

Figure 6. Raman spectra of the pristine supports and corresponding Pd supported composites (a), and comparison of the derived $I_{D} / I_{G}$ ratios (b).

When $0.25 \mathrm{mM} \mathrm{Pd(acac})_{2}$ is fully reduced and loaded on 1 $\mathrm{mg} \cdot \mathrm{mL}^{-1}$ of support in EG, a composite with a nominal $\mathrm{Pd}$ loading of $2.6 \mathrm{wt} \%$ is yielded. This metal loading is much lower than many commercial carbon supported noble metal catalysts with loadings of 10-40 wt \%. HER has been demonstrated a highly responsive reaction for even atomic scale noble metalbased electrocatalysts. ${ }^{55,56}$ Therefore, we choose the HER to probe the electrocatalytic activity of the as-prepared $\mathrm{Pd}$ supported composites in $0.5 \mathrm{M} \mathrm{H}_{2} \mathrm{SO}_{4}$. Figure 7a displays the LSV polarization curves with the four composite catalysts. As a common practice, the overpotentials at a current density of 10 $\mathrm{mA} \cdot \mathrm{cm}^{-2}\left(\eta_{10}\right)$ are compared in Figure $7 \mathrm{~b}$. We can see that $\mathrm{Pd} / \mathrm{NG}$ exhibits the smallest $\eta_{10}$ of $199 \mathrm{mV}$, which is lower than $\mathrm{Pd} / \mathrm{GO}(273 \mathrm{mV}), \mathrm{Pd} / \mathrm{rGO}(358 \mathrm{mV})$ and Pd/G (218 mV). Based on the preceding structural characterizations, the highest HER activity of $\mathrm{Pd} / \mathrm{NG}$ should be ascribed to the ultrafine Pd NP size and uniform size distribution, and potential metal-support interaction. Tafel analysis is further performed to provide mechanistic insight of the reaction pathway. The Tafel plots and Tafel slopes of fitted lines for the four composites are presented in Figure $7 \mathrm{c}$ and $7 \mathrm{~b}$, respectively. Tafel slopes of the composites fall in the range of $80-140 \mathrm{mV} \cdot \mathrm{dec}^{-1}$, suggesting that the initial Volmer step $\left(\mathrm{H}_{3} \mathrm{O}^{+}+\mathrm{e}^{-}+* \rightleftarrows \mathrm{H}^{*}+\mathrm{H}_{2} \mathrm{O}, 120 \mathrm{mV} \cdot \mathrm{dec}^{-1}\right)$ is the rate-determining step for the Pd-based catalysts. ${ }^{57}$ The Volmer step involves hydrated proton adsorption and electron transfer. The more conductive $G$ and NG thus facilitate the electron transfer for hydrogen adsorption and present smaller Tafel slopes than $\mathrm{Pd} / \mathrm{GO}$ and $\mathrm{Pd} / \mathrm{rGO}$. These results again demonstrate the positive role of NG support in attaining an efficient heterostructured catalyst.
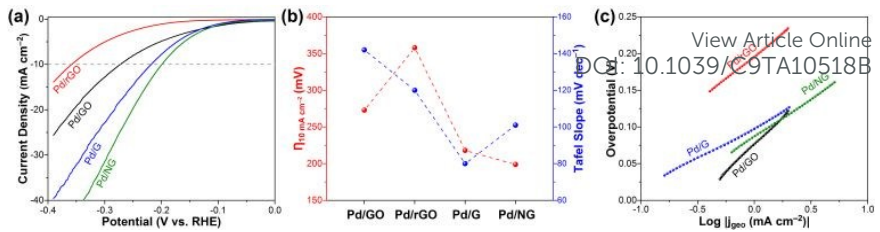

Figure 7. Polarization curves (a), overpotentials at $10 \mathrm{~mA} \cdot \mathrm{cm}^{-2}$ and Tafel slopes (b), and Tafel plots (c) of Pd supported on four graphene-based supports in argon-saturated 0.5 $\mathrm{M} \mathrm{H}_{2} \mathrm{SO}_{4}$.

\section{Pd/NG with Different Loadings}

Reducing the noble metal usage while maintaining its catalytic performance is important for developing cost-effective catalysts. To explore the size-dependent activity of Pd NPs for $\mathrm{HER}$, we irradiated $1 \mathrm{mg} \cdot \mathrm{mL}^{-1}$ of $\mathrm{NG}$ in EG solutions with different $\mathrm{Pd}$ concentrations of $0.125,0.25,0.375$, and $0.5 \mathrm{mM}$. The nominal Pd loadings of Pd/NG are 1.3, 2.6, 3.9, and $5.2 \mathrm{wt}$ $\%$. The corresponding composites are designated as $x$-Pd/NG, $x$ is the metal loading.

Figure 8a shows the XRD patterns of the pristine NG and four $\mathrm{Pd} / \mathrm{NG}$ composites. Apart from the characteristic peaks of NG, new diffraction peaks assigned to Pd phase are observed for all the Pd/NG. With increasing Pd loadings, intensity of these peaks strengthens and peak shape narrows down. Figure $S 8$ displays the bright-field TEM images of Pd/NG of different loadings and their corresponding PSDs. With increasing Pd loadings comes also larger crystallite size (Table S1), APS and severer NP aggregation, underscoring the importance in the optimization of Pd content on Pd/NG. SEM images of the four composites are displayed in Figure S9, in which similar surface morphology featuring fluffy graphene sheets is confirmed for all samples. In addition, Raman spectra of the pristine NG and four Pd/NG composites are presented in Figure $8 \mathrm{~b}$. Their $\mathrm{I}_{\mathrm{D}} / \mathrm{I}_{\mathrm{G}}$ ratios in Figure $8 \mathrm{c}$ are found to be almost unchanged, indicating the high structural stability of NG during dispersion and radiation.
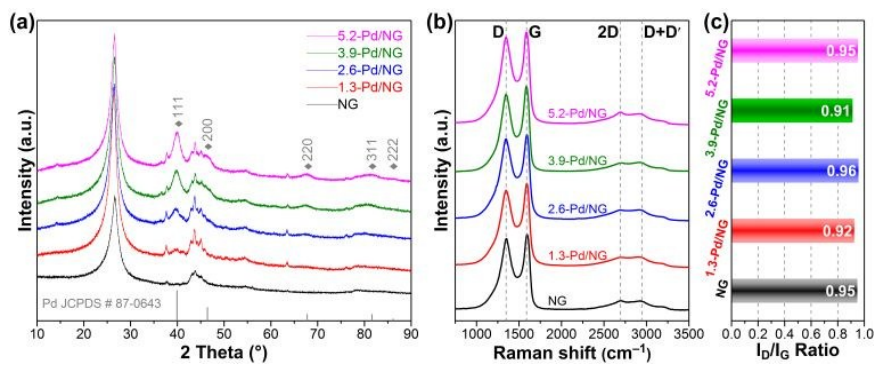

Figure 8. XRD patterns (a) and Raman spectra (b) of the pristine NG and Pd/NG with four Pd loadings of $1.3,2.6,3.9$, and $5.2 \mathrm{wt} \%$, and comparison of the derived $\mathrm{I}_{\mathrm{D}} / \mathrm{I}_{\mathrm{G}}$ ratios (c).

HER activities of the pristine NG and four Pd/NG composites are further tested. Figure 9a presents the LSV polarization curves in argon-saturated $0.5 \mathrm{M} \mathrm{H}_{2} \mathrm{SO}_{4}$. The $\eta_{10}$ data is taken and plotted in Figure $9 \mathrm{~b}$. Compared to NG with a large $\eta_{10}, 1.3-P d / N G$ and 2.6-Pd/NG yield significantly reduced $\eta_{10}$ of 286 and $199 \mathrm{mV}$, respectively, which conforms to the intuition that more metal endows with higher activity. Surprisingly, when further increasing the Pd loading, no substantial variation of the $\eta_{10}$ is observed for 3.9-Pd/NG (218 mV) and 5.2-Pd/NG (218 mV). 
Given that only surface and/or subsurface Pd atoms participate in the HER catalysis, this counter-intuitive observation should be attributed to the similar content of catalytically active $\mathrm{Pd}$ atoms for 2.6-Pd/NG, 3.9-Pd/NG and 5.2-Pd/NG. According to the Tafel plots in Figure 9c, the Tafel slopes are presented in Figure $9 \mathrm{~b}$. We can see that the four Pd/NG catalysts have similar Tafel slopes in the range of $100-140 \mathrm{mV} \cdot \mathrm{dec}^{-1}$, signifying that the Volmer step is the rate-determining step for all of the catalysts.
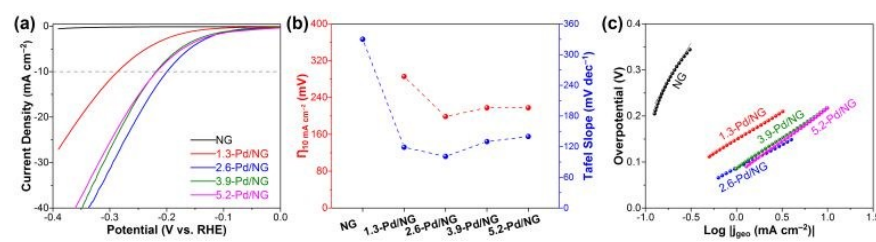

Figure 9. Polarization curves (a), overpotentials at $10 \mathrm{~mA} \cdot \mathrm{cm}^{-2}$ and Tafel slopes (b), and Tafel plots (c) of NG and Pd/NG with four Pd loadings in argon-saturated $0.5 \mathrm{M} \mathrm{H}_{2} \mathrm{SO}_{4}$.

To deepen the understanding of the role of NG in stabilizing Pd NPs, we analyze the chemical speciation and composition of $\mathrm{Pd}$ and $\mathrm{N}$ elements of Pd/NG using XPS. Full survey XPS spectra in Figure S10 corroborates the elemental composition. Figure 10a shows the XPS spectra of $\mathrm{Pd} 3 \mathrm{~d}$ region for four $\mathrm{Pd} / \mathrm{NG}$ composites. Through proper deconvolution and fitting, the $\mathrm{Pd}$ $3 \mathrm{~d}$ spectra can be resolved into two Pd species of dominant zero-valence $\mathrm{Pd}_{0}$ and minor slightly oxidized $\mathrm{Pd}_{\mathrm{ox}}$. Each species consists of two spin-orbit doublets, that is, $\mathrm{Pd} 3 \mathrm{~d}_{5 / 2}$ and $\mathrm{Pd}$ $3 d_{3 / 2}$. Under identical testing conditions, it is found that the XPS peak intensity increases progressively with the increase of $\mathrm{Pd}$ loading. The peaks at binding energies of 335.6 and $340.9 \mathrm{eV}$ belong to $\mathrm{Pd}_{0} 3 \mathrm{~d}_{5 / 2}$ and $\mathrm{Pd}_{0} 3 \mathrm{~d}_{3 / 2}$, respectively. Shift of the binding energy is not observed for different composites, indicating the similar chemical environment of $\mathrm{Pd}$.

XPS spectra of $N$ 1s region for NG and four Pd/NG composites are illustrated in Figure 10b. The $\mathrm{N}$ 1s spectra are deciphered into three species, including pyridinic, pyrrolic and graphitic nitrogen. Pyridinic and pyrrolic nitrogen refers to the substituted nitrogen that bonds with two carbon atoms, but forms a six-membered and five-membered ring, respectively. Graphitic nitrogen is formed by direct substitution of $\mathrm{sp}^{2}$ carbon. For the NG, peaks at binding energies of 398.2, 400.4 and $402.7 \mathrm{eV}$ are assigned to the pyridinic, pyrrolic and graphitic nitrogen, respectively. With the increase of Pd loading, all the nitrogen species show a gradual shift of their binding energies, especially for the graphitic nitrogen. The specific binding energy is detailed in Table S4. The change of binding energy readily signifies the occurrence of electron transfer. After Pd NPs are loaded on the NG, the electrons are donated from electron-rich Pd to electron-deficient $\mathrm{N}$. This electron transfer is believed to underlie the superior anchoring effect of Pd NPs on NG, emphasizing the critical role of nitrogen dopants. ${ }^{58}$ Table $\mathrm{S} 5$ lists the atomic and weight percentage of $\mathrm{C}, \mathrm{N}, \mathrm{O}$, and $\mathrm{Pd}$ of $\mathrm{NG}$ and $\mathrm{Pd} / \mathrm{NG}$. The nitrogen content of NG is found to be $\sim 5 \mathrm{wt} \%$, in line with the product specification from the supplier. Accordingly, we believe that the nitrogen content accounts for the upper limit of Pd loading. Once Pd loading exceeds this threshold, Pd NPs would tend to grow into larger sizes instead of being stabilized by available nitrogen äpäpts.3Besidels, ,the Pd weight percentage is again found to be dramatically higher than the nominal values. The commercial NG is already disclosed by Raman (Figure 6a and 8 b) to be rather graphite-like than single or few layer graphene-like. This result also highlights the potential of improving support quality to enhance the output of the supported catalysts.

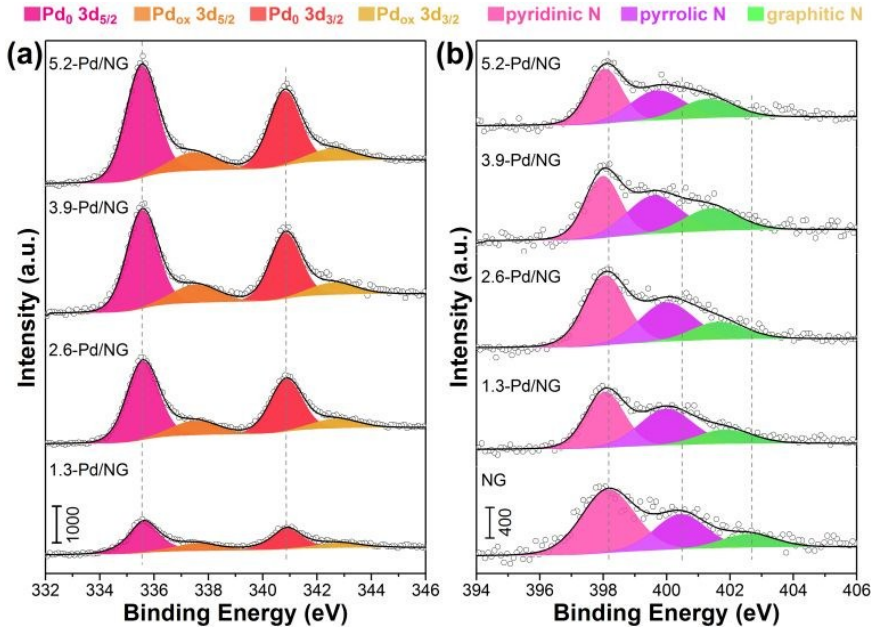

Figure 10. High-resolution XPS spectra of Pd $3 d(a)$ and $N$ 1s (b) regions for the pristine NG and Pd/NG with four Pd loadings of 1.3, 2.6, 3.9, and $5.2 \mathrm{wt} \%$.

\section{$\mathrm{Pt} / \mathrm{NG}$ and commercial Pt/CB}

To explore the versatility of this synthetic route, we further extend to the preparation of $2.6 \mathrm{wt} \% \mathrm{Pt} / \mathrm{NG}$ by substituting Pd with $\mathrm{Pt}$ and compare the HER activity to commercial 10 wt \% $\mathrm{Pt} / \mathrm{CB}$. Figure 11a shows the XRD patterns of pristine NG, Pt/NG and $\mathrm{Pt} / \mathrm{CB}$. Apart from the diffraction peaks of graphitic carbon, five characteristic peaks, indexed to cubic Pt phase with JCPDS card No. 89-7382, are observed for Pt/NG and Pt/CB. Comparison of the height and broadness of Pt peaks indicates a larger crystal size for $\mathrm{Pt} / \mathrm{CB}$ than $\mathrm{Pt} / \mathrm{NG}$. Figure $11 \mathrm{~b}$ presents the LSV polarization curves in argon-saturated $0.5 \mathrm{M} \mathrm{H}_{2} \mathrm{SO}_{4}$ together with the $\eta_{10}$ data in the inset. We can see that Pt/NG yields an even smaller $\eta_{10}$ of $39 \mathrm{mV}$ than the commercial Pt/CB (45 mV). Based on earlier results, we attribute the superior performance of Pt/NG to the smaller Pt NP size and favorable metal-support interaction between Pt NPs and NG. Tafel plots in Figure $11 \mathrm{c}$ give a Tafel slope of 31 and $28 \mathrm{mV} \cdot \mathrm{dec}^{-1}$ for $\mathrm{Pt} / \mathrm{CB}$ and $\mathrm{Pt} / \mathrm{NG}$, indicating that the HER rate is limited by the Tafel step $\left(2 H^{*} \rightleftharpoons H_{2}+2 *, 30 \mathrm{mV} \cdot \mathrm{dec}^{-1}\right)$, which accords well with the known fact that hydrogen desorption is relatively slow on $\mathrm{Pt}$.
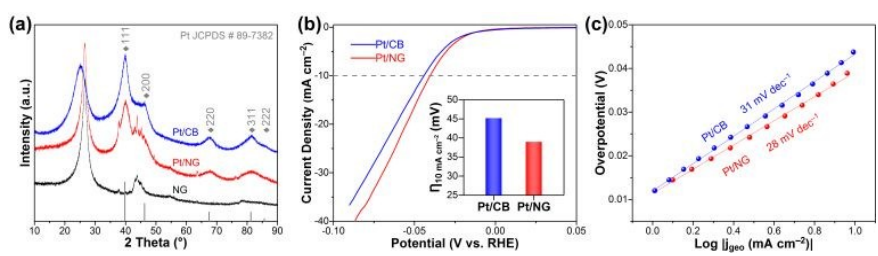

Figure 11. XRD patterns of pristine NG, $\mathrm{Pt} / \mathrm{NG}$ and $\mathrm{Pt} / \mathrm{CB}$ (a). Polarization curves (b) and overpotentials at $10 \mathrm{~mA} \cdot \mathrm{cm}^{-2}$ (inset), and Tafel plots (c) of Pd/NG and Pt/CB in argonsaturated $0.5 \mathrm{M} \mathrm{H}_{2} \mathrm{SO}_{4}$. 


\section{Conclusions}

Utilizing in-situ generated reducing species from solvent by gamma radiation, ultrafine $3.0 \mathrm{~nm}$ Pd NPs with a narrow size distribution are facilely prepared and loaded on graphenebased supports in the absence of surfactants and harsh reaction conditions. Guided by classical nucleation and growth mechanism, we clarify EG is a more suitable solvent than water. Control experiments reveal that NG outperforms three other graphene-based supports in controlling the NP size and distribution, and Pd/NG exhibits the highest HER activity. The HER activity of Pd/NG is found to reach a plateau once the Pd loading increases to $2.6 \mathrm{wt} \%$. The nitrogen dopants are revealed to play a contributive role in anchoring and dispersing the Pd NPs by electron transfer between Pd and doped N atoms. Further extending the synthesis to Pt metal gives Pt/NG that is even more active than the commercial Pt catalyst toward HER. This study provides useful guideline for radiation chemists to prepare advanced nanostructures.

\section{Conflicts of interest}

There are no conflicts to declare.

\section{Acknowledgements}

KG acknowledges EPSRC for a PDRA project by the grant EP/R042179/1. LHI thanks EPSRC for a PhD scholarship under the Doctoral Training Partnership scheme (grant EP/M507969/1). AB is supported as a Dalton Fellowship provided by Dalton Nuclear Institute, The University of Manchester. The authors thank Prof. Cinzia Casiraghi for providing graphene samples, Dr. Fabio Scenini and Dr. Litao Chang for TEM operation, Dr. Ruth Edge for Raman training, and Dr. Mark Isaacs (HarwellXPS) for XPS analysis. The authors acknowledge the support of Dalton Cumbrian Facility (DCF), a partner in the National Nuclear User Facility, the EPSRC UK National Ion Beam Centre and the Henry Royce Institute.

\section{References}

1 L. Wu, A. Mendoza-Garcia, Q. Li and S. Sun, Chem. Rev., 2016, 116, 10473-10512.

2 J. Lee, S. Zhang and S. H. Sun, Chem. Mater., 2013, 25, 12931304.

3 L. Zhou, Z. Zhuang, H. Zhao, M. Lin, D. Zhao and L. Mai, Adv. Mater., 2017, 29, 1602914.

4 L. S. Lin, J. Song, H. H. Yang and X. Chen, Adv. Mater., 2018, 30, 1704639.

5 H. Fujita, M. Izawa and H. Yamazaki, Nature, 1962, 196, 666-667.

6 H. Fei, J. Dong, C. Wan, Z. Zhao, X. Xu, Z. Lin, Y. Wang, H. Liu, K. Zang, J. Luo, S. Zhao, W. Hu, W. Yan, I. Shakir, Y. Huang and X. Duan, Adv. Mater., 2018, 30, 1802146.

7 Y. Zhou, S. H. Yu, C. Y. Wang, X. G. Li, Y. R. Zhu and Z. Y. Chen, Adv. Mater., 1999, 11, 850-852.

8 Y. Liu, L. He, C. Xu and M. Han, Chem. Commun., 2009, 43, 6566-6568.

9 I. V. Lightcap, T. H. Kosel and P. V. Kamat, Nano Lett., 2010, 10, 577-583.
10 C. Pacholski, A. Kornowski and H. Weller, Angew. Chem Int. Ed., 2004, 43, 4774-4777.

DOI: 10.1039/C9TA10518B

11 Y. Zhai, J. S. DuChene, Y. C. Wang, J. Qiu, A. C. Johnston-Peck, B. You, W. Guo, B. DiCiaccio, K. Qian, E. W. Zhao, F. Ooi, D. Hu, D. Su, E. A. Stach, Z. Zhu and W. D. Wei, Nat. Mater., 2016, 15, 889-895.

12 P. Maguire, D. Rutherford, M. Macias-Montero, C. Mahony, C. Kelsey, M. Tweedie, F. Perez-Martin, H. McQuaid, D. Diver and D. Mariotti, Nano Lett., 2017, 17, 1336-1343.

$13 \mathrm{H}$. Belmouaddine, M. Shi, L. Sanche and D. Houde, Phys. Chem. Chem. Phys., 2018, 20, 23403-23413.

14 H. Wei, K. Huang, D. Wang, R. Zhang, B. Ge, J. Ma, B. Wen, S. Zhang, Q. Li, M. Lei, C. Zhang, J. Irawan, L. M. Liu and H. Wu, Nat. Commun., 2017, 8, 1490.

15 H. Wei, H. Wu, K. Huang, B. Ge, J. Ma, J. Lang, D. Zu, M. Lei, Y. Yao, W. Guo and H. Wu, Chem. Sci., 2019, 10, 2830-2836.

16 T. F. Li, J. J. Liu, Y. Song and F. Wang, ACS Catal., 2018, 8, 8450-8458.

17 P. Liu, Y. Zhao, R. Qin, S. Mo, G. Chen, L. Gu, D. M. Chevrier, P. Zhang, Q. Guo, D. Zang, B. Wu, G. Fu and N. Zheng, Science, 2016, 352, 797-801.

18 J. D. Mangadlao, P. Cao, D. Choi and R. C. Advincula, ACS Appl. Mater. Interfaces, 2017, 9, 24887-24898.

19 J. L. Marignier, J. Belloni, M. O. Delcourt and J. P. Chevalier, Nature, 1985, 317, 344-345.

20 J. Grand, S. R. Ferreira, V. de Waele, S. Mintova and T. M. Nenoff, J. Phys. Chem. C, 2018, 122, 12573-12588.

21 J. Belloni, M. Mostafavi, H. Remita, J. L. Marignier and M. O. Delcourt, New J. Chem., 1998, 22, 1239-1255.

22 L. M. Alrehaily, J. M. Joseph and J. C. Wren, Phys. Chem. Chem. Phys., 2015, 17, 24138-24150.

23 L. M. Alrehaily, J. M. Joseph, A. Y. Musa, D. A. Guzonas and J. C. Wren, Phys. Chem. Chem. Phys., 2013, 15, 98-107.

24 I. Lee, S.-M. Kang, S.-C. Jang, G.-W. Lee, H. E. Shim, M. Rethinasabapathy, C. Roh and Y. S. Huh, J. Mater. Chem. A, 2019, 7, 1737-1748.

25 T. I. Sutherland, C. J. Sparks, J. M. Joseph, Z. Wang, G. Whitaker, T. K. Sham and J. C. Wren, Phys. Chem. Chem. Phys., 2016, 19, 695-708.

26 J. S. Cho, W. Jang, S. C. Mun, M. Yi, J. H. Park and D. H. Wang, Carbon, 2018, 139, 564-571.

27 T. Zhang, T. Wang, Y. Guo, Y. Zhai, A. Xiang, X. Ge, X. Kong, H. $\mathrm{Xu}$ and H. Ji, Sci. China Mater., 2018, 61, 1596-1604.

28 M. H. Miao, S. C. Hawkins, J. Y. Cai, T. R. Gengenbach, R. Knott and C. P. Huynh, Carbon, 2011, 49, 4940-4947.

29 R. M. Musat, A. R. Cook, J. P. Renault and R. A. Crowell, J. Phys. Chem. C, 2012, 116, 13104-13110.

30 X. Zhao, N. Li, M. Jing, Y. Zhang, W. Wang, L. Liu, Z. Xu, L. Liu, F. Li and N. Wu, Electrochim. Acta, 2019, 295, 434-443.

31 H.-J. Ahn, J.-S. Lee, H.-S. Kim, I.-T. Hwang, J.-H. Hong, J. Shin and C.-H. Jung, J. Ind. Eng. Chem., 2018, 65, 318-324.

32 Q. Zhang, S. Ye, X. Chen, X. Song, L. Li and X. Huang, Appl. Catal. B: Environ., 2017, 203, 673-683.

33 Z. Zhang, X. Cui, W. Yuan, Q. Yang, H. Liu, H. Xu and H.-L. Jiang, Inorg. Chem. Front., 2018, 5, 29-38.

34 P. Cao, J. Peng, S. Liu, Y. Cui, Y. Hu, B. Chen, J. Li and M. Zhai, Sci. Rep., 2017, 7, 16048.

35 K. Parvez, Z. S. Wu, R. Li, X. Liu, R. Graf, X. Feng and K. Mullen, J. Am. Chem. Soc., 2014, 136, 6083-6091.

36 V. K. LaMer and R. H. Dinegar, J. Am. Chem. Soc., 1950, 72, 4847-4854.

37 K. Huang, L. Zhang, T. Xu, H. Wei, R. Zhang, X. Zhang, B. Ge, M. Lei, J. Y. Ma, L. M. Liu and H. Wu, Nat. Commun., 2019, 10, 606.

38 K. N. Kudin, B. Ozbas, H. C. Schniepp, R. K. Prud'homme, I. A. Aksay and R. Car, Nano Lett., 2008, 8, 36-41.

39 A. C. Ferrari and D. M. Basko, Nat. Nanotechnol., 2013, 8, 235246. 
40 A. Ul-Hamid, A Beginners' Guide to Scanning Electron Microscopy, Springer International Publishing, 1st edn., 2018.

41 N. T. Thanh, N. Maclean and S. Mahiddine, Chem. Rev., 2014, 114, 7610-7630.

42 C. L. Wang and D. Astruc, Prog. Mater. Sci., 2018, 94, 306-383.

43 Y. Zhu, S. Murali, W. Cai, X. Li, J. W. Suk, J. R. Potts and R. S. Ruoff, Adv. Mater., 2010, 22, 3906-3924.

44 D. Chen, H. Feng and J. Li, Chem. Rev., 2012, 112, 6027-6053.

45 J. Liu, ACS Catal., 2016, 7, 34-59.

46 H. B. Zhang, G. G. Liu, L. Shi and J. H. Ye, Adv. Energy Mater., 2018, 8, 1701343.

47 K. Ding, D. A. Cullen, L. Zhang, Z. Cao, A. D. Roy, I. N. Ivanov and D. Cao, Science, 2018, 362, 560-564.

48 A. Wong, Q. Liu, S. Griffin, A. Nicholls and J. R. Regalbuto, Science, 2017, 358, 1427-1430.

49 S. Park, J. An, J. R. Potts, A. Velamakanni, S. Murali and R. S. Ruoff, Carbon, 2011, 49, 3019-3023.

50 S. Stankovich, D. A. Dikin, R. D. Piner, K. A. Kohlhaas, A. Kleinhammes, Y. Jia, Y. Wu, S. T. Nguyen and R. S. Ruoff, Carbon, 2007, 45, 1558-1565.

51 C. K. Chua and M. Pumera, Chem. Commun., 2016, 52, 72-75.

52 J. Kim, L. J. Cote, F. Kim, W. Yuan, K. R. Shull and J. Huang, J. Am. Chem. Soc., 2010, 132, 8180-8186.

53 D. Li, M. B. Muller, S. Gilje, R. B. Kaner and G. G. Wallace, Nat. Nanotechnol., 2008, 3, 101-105.

54 A. P. Kauling, A. T. Seefeldt, D. P. Pisoni, R. C. Pradeep, R. Bentini, R. V. B. Oliveira, K. S. Novoselov and A. H. Castro Neto, Adv. Mater., 2018, 30, 1803784.

55 N. Xuan, J. Chen, J. Shi, Y. Yue, P. Zhuang, K. Ba, Y. Sun, J. Shen, Y. Liu, B. Ge and Z. Sun, Chem. Mater., 2018, 31, 429-435.

56 M. Zhou, S. Bao and A. J. Bard, J. Am. Chem. Soc., 2019, 141, 7327-7332.

57 T. Shinagawa, A. T. Garcia-Esparza and K. Takanabe, Sci. Rep., 2015, 5, 13801.

58 Y. K. Zhou, K. Neyerlin, T. S. Olson, S. Pylypenko, J. Bult, H. N. Dinh, T. Gennett, Z. P. Shao and R. O'Hayre, Energy Environ. Sci., 2010, 3, 1437-1446. 


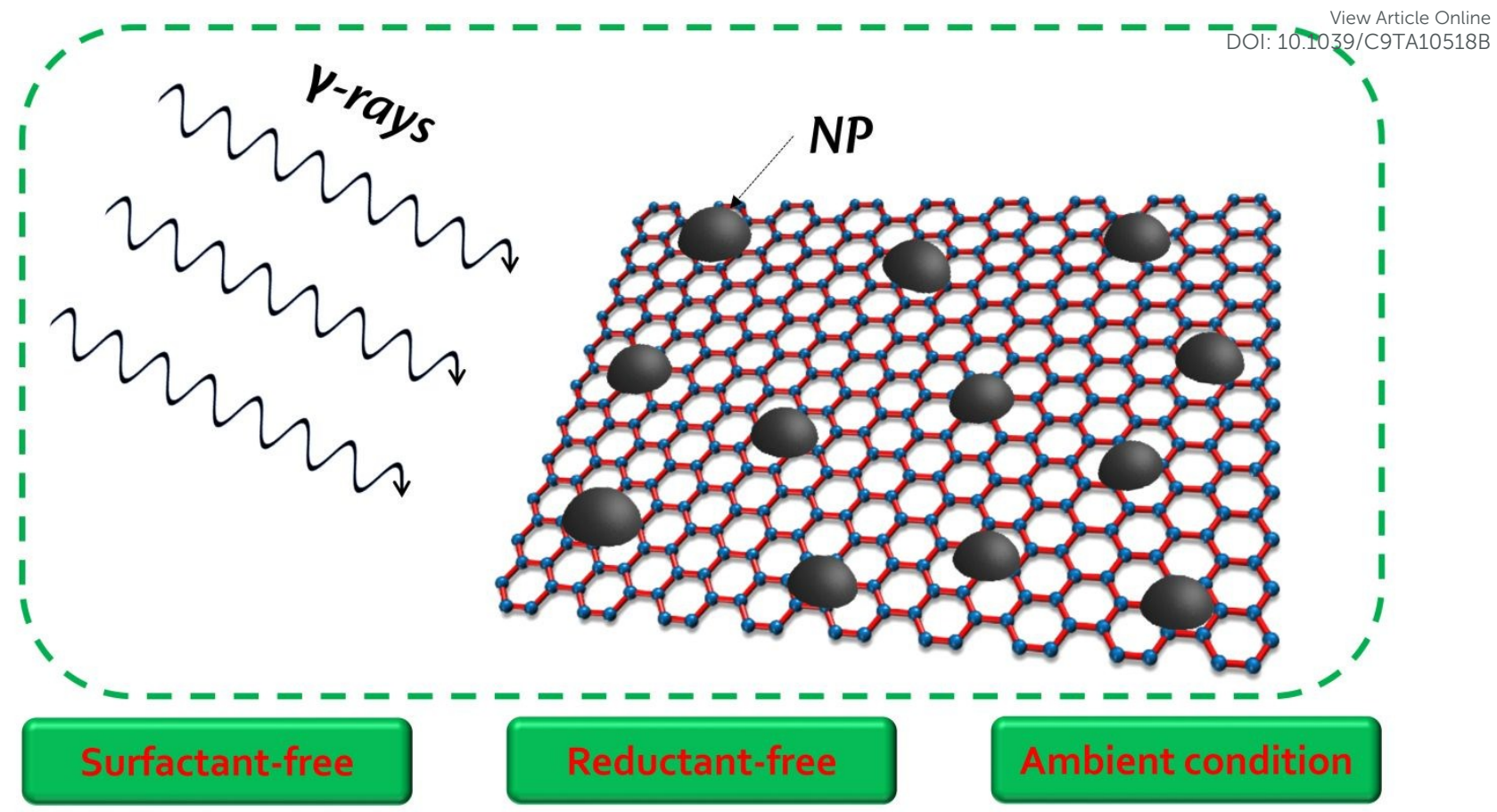

